


\title{
Associativismo e práticas de ócio (1994)
}

Autor(es): Gama, António

Publicado por: Imprensa da Universidade de Coimbra

URL

persistente: URI:http://hdl.handle.net/10316.2/32193

DOI: $\quad$ DOI:http://dx.doi.org/10.14195/978-989-26-0432-9_5

Accessed : $\quad$ 19-May-2017 17:39:42

A navegação consulta e descarregamento dos títulos inseridos nas Bibliotecas Digitais UC Digitalis, UC Pombalina e UC Impactum, pressupõem a aceitação plena e sem reservas dos Termos e Condições de Uso destas Bibliotecas Digitais, disponíveis em https://digitalis.uc.pt/pt-pt/termos.

Conforme exposto nos referidos Termos e Condições de Uso, o descarregamento de títulos de acesso restrito requer uma licença válida de autorização devendo o utilizador aceder ao(s) documento(s) a partir de um endereço de IP da instituição detentora da supramencionada licença.

Ao utilizador é apenas permitido o descarregamento para uso pessoal, pelo que o emprego do(s) título(s) descarregado(s) para outro fim, designadamente comercial, carece de autorização do respetivo autor ou editor da obra.

Na medida em que todas as obras da UC Digitalis se encontram protegidas pelo Código do Direito de Autor e Direitos Conexos e demais legislação aplicável, toda a cópia, parcial ou total, deste documento, nos casos em que é legalmente admitida, deverá conter ou fazer-se acompanhar por este aviso.

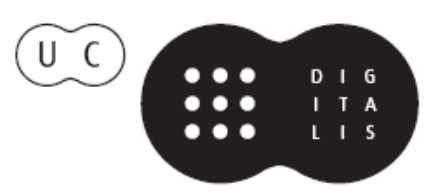


Norberto Pinto dos Santos

António Gama

Coordenação

\section{Lazer}

\section{Da libertação do tempo à conquista das práticas}


(Página deixada propositadamente em branco) 


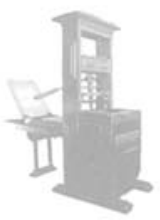

E

N

S

I

N

0

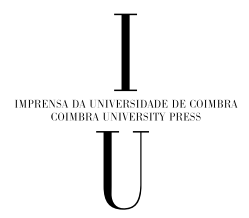


(Página deixada propositadamente em branco) 
Norberto Pinto dos Santos

António Gama

Coordenação

\section{Lazer}

\section{Da libertação do tempo à conquista das práticas}


(Página deixada propositadamente em branco) 


\section{Lazer}

\section{Da libertação do tempo à conquista das práticas}


COORDENAÇĀO EDITORIAL

Imprensa da Universidade de Coimbra

Email: imprensauc@ci.uc.pt

URL: http://www.uc.pt/imprensa_uc

\author{
CONCEPÇÁO GráfICA \\ António Barros \\ PRÉ-IMPRESSÃ́ \\ Paulo Oliveira \\ [PMP] \\ EXECUÇĂO GRÁFICA
SerSilito • Maia \\ ISBN \\ 978-989-8074-56-0 \\ Depósito LEGAL \\ 286421/08
}

OBRA PUBLICADA COM A COLABORAÇĀO DE:

\title{
FCT Fundação para a Ciência e a Tecnologia
}

MINISTÉRIO DA CIÊNCIA, TECNOLOGIA E ENSINO SUPERIOR Portugal

Programa Operacional Ciência, Tecnologia, Inovação do Quadro Comunitário de Apoio III 


\author{
António Gama \\ Centro de Estudos Sociais \\ Universidade de Coimbra
}

\title{
AsSOCIATIVISMO E PRÁtICAS DE ÓCIO*
}

O associativismo aparece como uma das formas de sociabilidade mais curiosas e instáveis nas sociedades modernas. Mau grado ser um fenómeno moderno, produto das condiçóes novas de desejo e de necessidade de associação geradas no seio das sociedades liberais, o associativismo tem-se transformado à medida das mudanças operadas nas sociedades, vindo a diminuir em muitos casos ou mesmo a desaparecer sem que outras formas pareçam emergir em sua substituição.

Daí que a muitos pareça cada vez mais que a nossa vida social está a descoberto, já que não parecem existir mais, entre o Estado e os indivíduos, estes grupos intermediários onde se operava a integração social e que eram igualmente factores de autonomia e de resistência da sociedade em relaçáo ao Estado. Por sua vez, o Estado integra cada vez mais a sociedade territorializando-se, ao mesmo tempo, de forma intensiva e difusa, através da descentralização e da emergência do que se vem designando por poder local. O Estado local que assim se configura, vai tomando a seu cargo muitos dos papéis antes desempenhados pelo associativismo. Este é marcado por uma ambiguidade, é Estado, porque extensão local do poder central, e aparece marginal quando é expressão de territorialidade local, defensor dos interesses locais como representante das populaçóes a nível local. O Poder local, em virtude da sua ambiguidade talvez como nível territorial de base da cidadania, toma a seu cargo algumas das funçóes clássicas do associativismo, anteriormente mais desvinculadas da matriz institucional das políticas do Estado. Além do efeito das transformaçóes do Estado, esta situação é também resultado da massificação cultural e do duplo sentido das suas máquinas (individualização do consumo/massificação da produção).

$\mathrm{O}$ advento da cultura de massas aparece associado à desertificação da sociedade: desaparecem as culturas e as solidariedades locais que podem concorrer com os meios massivos da comunicação e de manipulação. As nossas sociedades tendem a tornar-se colectividades de indivíduos separados, debruçados sobre a vida privada, impotentes e indiferentes, cada vez mais consumidores numa multidão solitária, cada vez menos

*Texto náo publicado, utilizado como texto de apoio para alunos de Geografia e Turismo, Lazer e Património. Versão de 1994. 
cidadão a corpo inteiro. A ilusão da cidadania, cada vez mais solitária na escolha, está na directa proporção da sua condição de espectador, que ao invés de fazer a opinião é feito pela opinião.

\section{Mudanças sociais, o tempo livre e os ócios}

É tanto mais preocupante este estado de coisas quanto a perda de sentido vem aliada a um crescimento do tempo fora do trabalho. Nas sociedades modernas conta cada vez mais o tempo designado como tempo livre, geralmente associado com os ócios ou lazeres. O progresso desencadeado no seio das sociedades industriais implicou a transformaçáo de diversos domínios os quais contribuíram grandemente para o aumento do tempo livre e a diversificação dos ócios. Entre os factores que devem ser referidos figuram:

- o alongamento da duração de vida e a diminuição da idade de reforma;

- a evolução dos modos de vida no seio da família e da sociedade;

- a maior abundância de bens materiais;

- a aparição de novos modos de vida e de trabalho;

- a uniformização das condiçóes de vida urbana e rural;

- o encurtamento da semana de trabalho;

- a urbanização progressiva, a generalização do ensino, a cultura de massa e a eliminação do analfabetismo.

O ócio, embora condicionado pelas estruturas económicas e sociais, ou seja pela produtividade do tempo de trabalho, já não representa hoje apenas o tempo livre disponível de cada dia ou a antítese do trabalho, mas um período de tempo de recuperação e de realização. Tornou-se um domínio de crescente importância, de tal modo que a sua concepçáo se alargou e enriqueceu, quer quanto ao seu conteúdo quer quanto à sua finalidade. Inicialmente, apenas com uma importância secundária no tempo diário, converteu-se, a pouco e pouco, num dos elementos fundamentais da constituição da personalidade complexa do homem contemporâneo. Esta mudança foi acompanhada da alteração progressiva do carácter tradicional dos ócios, para dar lugar a uma plêiade de práticas e de situaçóes correlativas da modernidade. De simples recuperaçáo de forças ou de um prazer puramente pessoal converteram-se num meio susceptível de criar e formar personalidades harmoniosas e uma sociedade equilibrada. Mas, o risco do seu reverso não é desprezível. A crescente alienação e manipulação produzidas pela massificação, porque os ócios, enquanto produtos da sociedade industrializada, são um elemento da vida e constituem uma afirmação social, não se convertem menos numa forma de consumo, já que implicam despesas e estas, em termos económicos, são também função dos meios disponíveis, convertendo na realidade a ilusória igualdade nos ócios numa nova desigualdade.

\section{O associativismo: génese e transformaçôes}

As formas de associativismo estiveram desde sempre ligadas à prática dos ócios. As primeiras referências de associativismo fora da esfera política e das instituiçóes 
societárias constitutivas da arquitectura social (família, Estado, Igreja) aparecem como formas de associativismo popular, mais especificamente de meios operários, e desenvolveram-se principalmente desde meados do século XIX. Apareciam então prosseguindo diversas funçóes, desde a prestação de serviços, de entretenimento e de educação até a intentos de reforma social.

Estas associaçóes culturais ou colectividades, como vulgarmente vêm a ser chamadas, patenteiam identidades atinentes ao grupo social ou profissional ou mesmo ao bairro ou à localidade. Esta dupla pertença faz destas colectividades criadoras de vínculos sociais ou territoriais com predominância para a escala local, fortalecendo e alargando as vizinhanças. Na caracterização destas identidades, no dizer de J. M. Viegas, "a própria denominação das colectividades incluindo o nome da terra - cidade, vila ou lugar /bairro - tem um carácter emblemático, assim como julgamos não ser isenta de significação a inclusão da designação operária em algumas delas" (Viegas, 1984).

Se muitas destas associaçóes tem como objectivos práticas culturais, (como música, teatro, leitura), a grande maioria dedica-se a actividades desportivas, inicialmente como promotoras de práticas muitas converteram-se em promotores de espectáculos desportivos que por força dos tempos a profissionalização obrigou. Estas colectividades, nomeadamente as desportivas, desempenham um papel importante na definição das pertenças territoriais. No dizer de J. Gaspar "em Portugal é sobretudo o desporto que adquire o valor de símbolo do território de que cada indivíduo se apropria - do lugar, da vila, da região e do país” (Gaspar et al., 1981). Se muitos destes clubes ainda aparecem com forte ligação ao local e ao grupo social que lhe esteve na origem, deve assinalar-se o facto de os clubes de futebol revelarem um carácter interclassista, integrando na mesma colectividade diversas camadas sociais. Muitos clubes houve que por transformaçóes diversas, umas da base social local, outras pelo alargamento da base territorial e social, se convertem em expressão de territorialidades mais vastas, como regionalismos ou mesmo nacionalismos, extensão essa que evidencia ainda mais a característica interclassista.

No que se refere à territorialidade, além destes tipos de colectividades, devem ainda ser referidos os grupos folclóricos e as bandas musicais que, pelas características de cada um, expressam modos de articulação entre a tradição, a modernidade e as territorialidades. As primeiras com objectivos no âmbito da preservaçáo e exaltação das tradiçôes locais (música e dança), no dizer de Pedro-Rego (1993), as segundas, apresentam-se mais arreigadas às territorialidades marcadas pela tradição, com preocupaçóes mais diversas no campo musical e de expressão mais urbana, denotam na sua fundação uma maior modernidade. Uma e outra expressam claramente um valor de símbolo do território com o qual se identificam.

Se o associativismo se apresentou como uma força na representação das localidades preenchendo uma diversidade de práticas, este aparece hoje deslocado e entregue quase em exclusivo aos grupos desportivos, particularmente aos de futebol. Têm vindo a desaparecer muitas das funçôes, nomeadamente no âmbito da sociabilidade participativa e no da prática da cidadania, que estas colectividades fomentavam. Viegas refere, a propósito deste estado de coisas, que "em relação às colectividades populares se regista, em muitos casos, um desinvestimento associativo, que se manifestam um reduzido número de criatividade cultural, restando apenas, quanto às suas funçôes, como um espaço de sociabilidade e como colectividade de prestação de alguns serviços” (Viegas, 1984). 
Hoje, novas formas de associativismo tendem a surgir, agora mais ligados a interesses gerais ou particulares, muitos deles com expressão territorial local. Assim, associaçóes de tipo novo aparecem orientadas para questóes como o ambiente, o consumo, as ciências e as tecnologias, deixando o domínio da cultura entregue à dominaçáo dos meios de produção de massa.

Um olhar mais atento pelo domínio dos ócios e dos tempo livre, ajudar-nos-á a entender melhor estas mudanças e ao mesmo tempo a apontar alguns caminhos no sentido de reinverter a situação presente, pelo interesse que estas colectividades têm no reforço da sociabilidade local e da cidadania.

\section{3. Ócios e tempo livre}

Passando por cima de uma abordagem mais detalhada acerca das concepçóes do tempo livre e do ócio, da sua génese e evolução e da relação com as sociedades, propomos o ócio como designando três ordens de facto diferentes, como tempo, no que se relaciona com o tempo livre, como actividade e, finalmente, como atitudes:

1 - Como quadro temporal (nas diferentes acepçóes), interrupção ou suspensão das actividades, paragem do trabalho (tempo de pausa, tempo livre do fim do dia após o trabalho, fim-de-semana, férias anuais, reforma, etc.);

2 - Como actividade ou conjunto de actividades: neste conjunto, enumeram-se uma grande série de ocupaçóes de natureza variada, do bricolage aos desportos, da exposição aos media à exposição ao sol, do passeio de automóvel às viagens a longa distância, a lista é ilimitada;

3 - Como atitudes, disposiçóes pessoais, conceitos individuais ou colectivos em relação ao tempo ou à acção (Lanfant, 1972).

Em suma, tempo livre e ócio têm a ver com as funçóes que desempenham na sociedade. Mas as funções são realizadas por diversas práticas exercidas em relação ao tempo (duraçáo) e ao espaço (espacialidade).

Estas relações pressupóem uma referência às funções do ócio, ou melhor, às funçôes das práticas do tempo livre.

Por sua vez, a relação indivíduo/sociedade, juntamente com o problema da integração social aparece como um dos problemas mais candentes da vida das sociedades modernas, em consequência da acentuação da individualização, dos riscos de solidão, com profundas alteraçôes nas formas de comunicação, com fragmentação e deterioração das relaçóes de nível interpessoal. A divisão de trabalho, a separação espacial entre lugares de residência e de trabalho, a crescente natureza individual do consumo dificultam os aspectos de socialização com especial relevo para os que tradicionalmente se encontram realizados pela família. Com uma função de integração social de grande importância, o agrupamento familiar foi perdendo esse papel em favor de outras instituiçóes, em que se destacam as de natureza associativa, especialmente nas sociedades urbanas e industriais. Novas instituiçóes aparecem a desempenhar o papel de núcleo social das actividades de ócio. De entre estes núcleos de socialização tomam particular evidência para as estruturas associativas, como os clubes, associaçóes e grupos de identificação social ou cultural, tanto na criação de condiçóes das práticas, como organizadores de espectáculos de massas, festas, festivais, espectáculos desportivos. 


\section{O associativismo e práticas dos ócios}

O ócio e as práticas a ele ligadas, como fenómenos da sociedade não podem ser desligados, como se referiu, da sua dimensão económica relacionando-o com o ciclo da produçáo/consumo, visto que uma sociedade em que as actividades ligadas ao consumo tomam uma importância crescente, ao ponto de se lhe atribuir a designação de sociedade de consumo, não podem ser ignoradas as actividades de ócio como inseridas nesse circuito.

A produção de ócios, ou a indústria dos ócios segundo alguns autores, transformou-se numa cadeia das mais importantes no contexto das economias das sociedades modernas, nomeadamente nas designadas por pós-industriais, como é o caso do desporto, dos grandes festivais de música ou de cinema, entre outros.

Mesmo algumas actividades que aparentemente são consideradas como funçôes essenciais de manutenção da vida, como a alimentação, apresentam uma ambiguidade na sua caracterização, já que quando praticadas em determinadas ocasióes e em certos lugares, podem envolver formas mais ou menos nítidas de associativismo, acentuando a funçáo de socialização e o papel hedonista. Com elas aparecem ligadas formas de associativismo formal, traduzido em reunióes regulares e muitas vezes configurando formas institucionais, como os grupos excursionistas.

A importância que vimos atribuindo ao domínio dos ócios nas sociedades modernas, resultado de uma longa evolução e de uma série de mutaçóes que não cabe no âmbito deste texto particularizar, suscita-nos uma breve referência a uma tipologia das práticas, na medida em que a sua natureza, frequência e grau de exigência vêm a demarcar, no que respeita ao associativismo, as fronteiras de vinculação, de nível de participação, de espectáculo, de ócio ou negócio.

A diversidade das actividades ligadas aos ócios e às situaçóes em que se praticam, isto é, dos lugares e dos tempos dessas actividades, tornam difícil uma ideia definida das suas práticas. A infinidade e diversidade deu ao aparecimento de várias classificaçóes, que procuram dar conta, de forma distinta, das características e das diversas situaçóes da ocupaçáo dos tempos livres ou da sua maior ou menor modernidade, nomeadamente, de que modo se repartem, que tempo ocupam, em que lugares se praticam, e que meios técnicos envolvem.

Por exemplo, Ahtik (1955) opõe ócios tradicionais, como conferências, leitura, música, arte, a ócios modernos, os quais são consequência de invenções, o automóvel, a rádio, o cinema. Uma outra, devida a Lynd (1925), à luz do progresso e no desenvolvimento da cultura de massa, à cultura tradicional (vida familiar, saídas locais, café, associativismo local), sucede a cultura humanista (conferências, círculos de educação popular) e, por fim, a cultura de massa (emissôes de rádio, cinema) (Dumazedier, 1974).

Outras há que procuram antes a diferenciação dos tipos de ócio segundo as suas características formais. Por exemplo, Havigurst (1955) define onze categorias entre as quais se contam tipos como participação em grupos, viagem de recreio, participação em actividades desportivas, televisão e rádio, trabalhos manuais, actividades de imaginação, visitas a amigos e familiares.

Kaplan (1973) apresenta uma das mais sugestivas tentativas propondo uma repartição das actividades do ócio em seis tipos principais, relacionando-os a seis centros de interesse: 
Por último, Dumazedier, autor com larga experiência neste domínio de estudos e na implementação das suas práticas, define tipos em que alia uma perspectiva sincrónica, associada a um critério de desenvolvimento cultural. Assim aponta três grandes grupos: ócios físicos, artísticos, práticos, intelectuais e sociais (Dumazedier, 1974).

Neste percurso a propósito da classificação das actividades do ócio mostra a dificuldade de uma classificação definitiva e como os contextos sociais e temporais dessas práticas podem ser decisivos na sua avaliação. Por isso, e na impossibilidade de uma elaboração plenamente satisfatória, optar-se-á, pelas necessidades práticas do estudo e pelos objectivos de uma relação com o associativismo, por uma classificação dos tipos de ócio, algo semelhante à de Dumazedier proposta por Sue (1981). Os limites entre os tipos são fluidos e apenas, para facilitar a inteligibilidade dos fenómenos, se separam, deparando-nos com dificuldades constantes. Uma característica comum é que todos, em graus diversos, contribuem tanto para o desenvolvimento cultural como para a socialização e por isso, quer num quer noutro aspecto, interessam ao associativismo.

Distinguiremos as quatro grandes categorias de actividades de ócio segundo Sue, 1980).

1. ócios físicos, 2. ócios práticos, 3. ócios culturais, 4. ócios sociais

O primeiro grupo, os ócios físicos, considera as actividades que implicam a manutenção do corpo, as práticas culturais de expressão física do indivíduo. Estas visam procurar uma sensação de descanso físico. "Estas actividades são tanto mais estimadas quanto o modo de vida urbano reduziu as possibilidades de expressão física do indivíduo. As condiçôes de trabalho multiplicam os factores de constrangimento físico e de tensão nervosa. O descanso físico é um meio de descontracção privilegiado.” (Sue, 1980: 83). Por isso torna-se uma necessidade crescente, que se vê adoptada cada vez mais, sobretudo pelas populaçôes urbanas.

Salientam-se três tipos principais que se diferenciam pelo grau de empenhamento, intensidade, periodicidade e grau técnico das suas práticas e pela componente associativista que envolvem.

O passeio como ócio físico é um elemento de descontracção muito frequente. Entre estes, o passeio pelo campo, praticado pelas populaçóes citadinas têm uma grande popularidade, evidenciando o desejo de espaços livres, a procura de calma e de ar puro. Da mesma forma, poderemos englobar neste tipo outras formas de passeio como o movimento inverso das populaçóes campesinas em direcçáo à cidade, os passeios pela montanha, etc. Maioritariamente praticado fora do âmbito do associativismo, apresenta contudo algumas formas curiosas de organizaçáo deste tipo de que destacamos os grupos excursionistas, onde se aliam principalmente interesses culturais ou de gosto da natureza.

Por seu lado, o ócio desportivo, implica já um grau diverso de empenhamento, de esforço físico e de periodicidade. Pode considerar-se um estádio superior de actividade física podendo as práticas ser feitas em diversas formas de relação: solitárias, em família, em grupos, em particular no quadro do associativismo clubístico. Os jogos assumem neste tipo uma evidência maior, desde os jogos tradicionais aos modernos. Entre estes poderemos referir o atletismo, o ciclismo, o footing, o ténis e outros jogos de raquete, os diversos jogos de bola, o hipismo, etc. Geralmente praticados fora de casa, em ginásios ou ao ar livre, necessitam de espaços, com maior ou menor extensão, mais apropriados senáo especializados, como campos desportivos, pistas, torna-os 
dependentes cada vez em maior grau de colectividades ou de outras instituiçóes tanto nas práticas como na criação e manutenção de infra-estruturas.

Por último, o desporto. É um ócio muito menos praticado, pois requer um maior esforço físico e uma prática mais contínua e um quadro associativo, mais organizado e profissionalizado. Tipos como a natação, a ginástica, o futebol e o atletismo são práticas das mais populares tendo uma significação social de duas facetas. Um aspecto diz respeito à prática e aos praticantes pelo empenhamento, periodicidade em que a fronteira entre ócio e trabalho se atenua. O outro concerne à dimensão espectáculo que comporta a separação entre praticante e espectador das práticas. O futebol é exemplar quanto a esta dualidade: é uma prática desportiva para os jogadores e um espectáculo para quem vê. Quer na implementação da sua prática, quer na sua promoção como espectáculo, pelo facto de desempenhar uma muito grande importância na ocupação do tempos livre e por ser condição da sua realização, o futebol aparece como uma das práticas com maior importância no âmbito do associativismo. Além disso, assinale-se ainda, a emergência de fenómenos de identificação acima referidos que, todos os domingos, as multidóes que acorrem aos espectáculos de futebol ilustram, projectando nessa prática um imaginário de identificação, tanto social, como individual.

O segundo grupo, os ócios práticos, englobam todas as actividades que necessitam de uma realização concreta e um qualquer trabalho manual. A bricolagem, a jardinagem, os trabalhos de pintura, de lavores são alguns dos exemplos destas práticas. Realizados em contextos diversos, afirmam-se mais pela individualidade, colocando-se por isso na maioria fora do associativismo.

A própria natureza destas práticas coloca algumas dúvidas à sua consideração como ócios. No entanto, segundo R. Sue, “o seu carácter utilitário permitirá considerá-los como prática de ócio” (Sue, 1980: 85). Esta questão levaria a uma discussão que ultrapassa o âmbito deste texto, não sem assinalar que parece não haver contradição entre utilidade e ócio, já que todo o ócio tem utilidade. Nesse sentido poderemos afirmar que alguns dos atributos definidos para caracterizar o ócio, por parte de alguns autores, enfermam de uma acentuada visão idealista. Neste tipo de práticas de ócio manifesta-se uma separação de práticas segundo o sexo que se radica em hábitos culturais fortemente enraizados.

Um terceiro grupo, que engloba as práticas designadas por ócios culturais, aparece como um domínio privilegiado do interesse dos movimentos associativistas. Campo difícil de delimitar já que a própria definição de ócios culturais levanta algumas dificuldades, nomeadamente pelas diferentes modos do que se entende por cultura. Este termo está impregnado de diferentes significaçóes, como mostra, por exemplo, Williams, ao estudar o final do século XVIII e princípio do século XIX, - a mesma palavra abarca toda uma série de significaçóes que se foram justapondo umas às outras como estratos de sedimentação. De uma concepção de cultura de alguma coisa passou aos finais do século XVIII ao de cultura como coisa existente. Segundo esta acepção, a cultura foi sendo: primeiramente "um estado geral ou um hábito do espírito", próximo da ideia de perfeição humana; em segundo lugar "o estado geral do desenvolvimento intelectual no conjunto da Sociedade"; em terceiro lugar, "o conjunto das artes"; em quarto, numa época mais tardia do século XIX, "todo um modo de vida, material, intelectual e espiritual" (Williams, 1961: 16). 
Neste texto, pelo âmbito que envolve, situamo-nos principalmente na fronteira das duas acepçóes amplas da palavra cultura: a de actividades intelectuais. Neste sentido, implica aprendizagem, e por esse facto está relacionada com os processos educativos nos seus contextos sociais. Pode envolver ainda um segundo, como modo de vida de uma sociedade ou de um grupo social habitualmente usado por antropólogos e sociólogos, o qual, como refere R. Williams, aparece tardiamente, durante o século XIX. Por essa razáo, as práticas que as pessoas desenvolvem no seu ócio são culturais em sentido amplo e permitem discernir os sentidos de cultura, por um lado, e as variaçóes de subculturas existentes no interior das sociedades, por outro.

Geralmente associados a determinadas funçôes, os ócios como práticas culturais, no sentido de actividades intelectuais, são fundamentais no desenvolvimento e expansão da personalidade. "Para o homem que trabalha, toda a actividade de participação activa na vida cultural, isto é toda a actividade de criação ou compreensão de uma obra, de qualquer natureza que seja, é uma actividade de ócio.” (Dumazedier, 1962: 123). As actividades culturais são necessárias à compreensão do ambiente, da estrutura social, e, consequentemente, à boa inserção social e são-no também ao desenvolvimento do sentido artístico, factor de realização pessoal. As suas expressóes formais, ao mesmo tempo, práticas, meios técnicos e contextos, são a televisão, rádio, festas, teatro, cinema.

Diversas tanto na sua repartição temporal e espacial como social, variam com as diferentes exigências de concentração e empenhamento dos participantes que em muitos casos são função dos níveis de rendimento, posição de classe e estatuto social das pessoas. Menos difundidos que outros, os ócios culturais envolvem uma percentagem de praticantes pouco significativa, na medida em que exigem um grau de participação mais profundo. $\mathrm{O}$ associativismo desempenha neste domínio um papel fundamental, de que são expressão do sem número de colectividades implicadas. Diferentemente repartidos na população são os que fazem surgir, mais que qualquer outras formas de ócio, desigualdades sociais muito profundas nas respectivas práticas. Poderemos dizer que são apanágio de minorias pois "não é difícil mostrar que os ócios, longe de atenuar as desigualdades dos diferentes grupos sociais em relação à cultura, antes, pelo contrário, as revelam à luz do dia” (Cronic, 1972: 383).

Apenas o ver televisão e o ouvir rádio figuram entre os ócios culturais cuja a assiduidade é inversamente proporcional ao lugar ocupado na hierarquia social. O ver televisão pode ser considerado como um "fenómeno cultural que tende a ser comum a todas as classes, todas as categorias sociais" (Dumazedier, 1962: 156), mas que pela sua natureza conduz a uma mera atitude passiva do espectador. Apresenta, no entanto, diferentes níveis de assistência, com especial incidência nos fracos índices de participação das camadas sociais com níveis culturais mais evoluídos e mais exigentes. A rádio, embora vítima da extensão de audiência da televisão, desempenha ainda um largo papel na ocupação dos tempos livres. A importância da rádio mantém-se pela feição mais participativa, pela comunicaçáo com os ouvintes, que veio a assumir como consequência de um concorrente importante como a televisão.

Embora com níveis de participação menores, os espectáculos de cinema, teatro, concertos musicais, bailados, ocupam um lugar nobre entre os ócios culturais. Apesar de envolverem um menor número de pessoas, náo deixam de ser importantes, quer pela condiçáo diversa do modo como são usufruídos como pelo sentido de prazer e de 
enriquecimento do espírito que despertam. De simples espectador a actor, de consumo ou de prática individual a colectiva, do lugar privado ao público, as possibilidades de realização são tão diversas que se torna difícil em poucas linhas dar conta de tamanho inventário. Como fenómeno da modernidade, estes ócios culturais denotam a instabilidade que a enforma, revelando uma sensibilidade tanto aos gostos e às modas como aos maravilhosos instrumentos que a indústria foi inventando para os ócios.

O cinema, o teatro, a música e o bailado são das práticas culturais socialmente mais valorizadas visto que associam motivação e informação da parte dos participantes implicando do espectador ou do praticante uma maior exigência cultural do que noutros tipos de ócio da mesma natureza. Poderemos considerá-las como práticas culturais activas, porque pressupóem iniciativa, implicam deslocação a locais específicos e requerem preparação. Por isso, estes ócios são considerados elitistas, sendo a sua prática "fortemente influenciada pela categoria socioprofissional e o nível de instrução" (Sue, 1980: 95).

Entre os ócios culturais, o teatro e a música têm desempenhado, pelo carácter socializador e colectivo, um papel de grande importância no desenvolvimento do fenómeno associativista, assegurando as condiçôes logísticas e de sociabilidade necessárias à sua realização. Pelo facto de hoje muitos desses papéis terem sido incorporados por outras instituiçóes, da escola à empresa, integradas pelos difusores da cultura de massas, da rádio à televisão, o associativismo parece bem longe de outros tempos, atravessar uma crise paralela à que atravessam certos lugares de realização de espectáculo, nomeadamente o cinema.

Por último, o domínio dos ócios sociais compreende todas as práticas de ócio ou de preenchimento do tempo livre em que predomina a actividade relacional, e por essa razão fortemente ligados ao associativismo. Aparecendo por vezes associados com uma actividade secundária, como tomar café, beber um copo, ir ao restaurante, a sua importância na socialização do indivíduo é primordial, desde o nível família ao da comunidade, como ao dos estratos socioprofissionais e políticos. O seu significado nas relaçóes de sociabilidade nos níveis extra-familiares são tão significativos que se denotam pelos tipos de lugares a que dão ocorrência e evidenciam diferenciaçóes e segregaçóes acentuadas expressas por diversos símbolos, de classe, de profissão, de etnias, de castas culturais. Deve assinalar-se aqui o papel desempenhado por clubes e colectividades locais no fomento de actividades culturais, numa acçáo educativa e de desenvolvimento de cultura e de integraçáo social e na criação de espaços de cidadania, nomeadamente nas áreas urbanas e suburbanas onde foram e têm sido um factor muito importante no desenvolvimento das práticas culturais e de sociabilidade e que hoje, a dominação das formas de cultura de massa e os instrumentos com ela relacionados têm esvaziado as funçóes e as condiçóes das práticas.

\section{Que futuro para o associativismo?}

Da diversidade de situaçóes nas práticas, devem ser destacadas a necessidade de contextos de associação para a sua realização e onde o associativismo tem tido um papel de maior relevo. Este embora aparecendo como um fenómeno moderno, associado à emergência das sociedades urbano/industriais, tem apresentado mudanças, quer nas 
funçôes quer na população envolvida que levam a questionar sobre o seu futuro. Se por um lado, os instrumentos da cultura e da recreação privatizaram e integraram no mundo dos negócios muitas das suas funções, o seu reconhecimento social generalizado levou à sua incorporaçáo na Escola ou noutras políticas do Estado. A perda de muitas das suas funçôes levou à estagnação, foi esvaziando uma das esferas de relação social no âmbito das comunidades locais, onde se operava a integração social. No que se refere às colectividades populares assiste-se a uma perda de importância da criatividade cultural, restando como espaço de sociabilidade e de prestação de serviços. Em substituição das formas tradicionais do associativismo têm emergido, por outro lado, outras de tipo novo, as quais deslocam o seu investimento para sectores como os do ambiente, do consumo, das áreas profissionais, da ciência e das tecnologias.

De uma forma ainda esquemática, parece que se deva questionar qual o futuro das colectividades dentro do âmbito das praticas modernas do ócio, em particular no domínio dos ócios de tipo cultural?

Em primeiro lugar, há que inventar novas forma de articulação entre o desfrute privado e a partilha social dos bens culturais fomentando focos de interesse que permitam a captação de novos participantes e principalmente de participantes novos.

Em segundo, e perante o desafio das novas tecnologias do ócio, implementar uma renovação de funçôes e objectivos, procurando as colectividades, pelo debate e por novas experiências, conjugar os saberes tradicionais e de expressão local com as formas de cultura de massa e com os meios técnicos modernos.

Por fim, conjugar o papel do associativismo como lugar de práticas e como promotor de espectáculos fomentando, por um lado, o associativismo dos indivíduos, buscando novos interesses, mais actuais, sem perder os de expressão local, e, por outro, lançar as redes de um associativismo inter-municipal no sentido de propiciar o acesso a formas de expressão cultural mais raras e caras, domínio onde o papel das autarquias pode vir a ser relevante.

\section{Bibliografia:}

Carroux, J. 1979, 'La démocratie par l'association?', Esprit, no especial, Seuil, Paris.

Coronio, G. R. \& Muret, J. P. 1977, Loisir, du mythe aux réalités, C.R.U., Paris.

Dumazedier, J. 1962, Vers une civilisation du loisir, Éditions du Seuil, Paris.

Dumazedier, J. 1974, Sociologie empirique du loisir. Critique et contre-critique de la civilisation du loisir, Editions du Seuil, Paris.

Dumazedier, J. 1988, Révolution culturelle du temps libre, 1968-1988, Méridiens Klincksiech, Paris.

Dumazedier, J. et al. 1971, Ocio y sociedad de clase, Fontanella, Barcelona,

Dumazedier, J. e Rippert, A. 1966, Loisir et culture, Éditions du Seuil, Paris.

Dumazedier, J. \& Samuel, N. 1976, Societé educative et pouvoir culturel, Éditions du Seuil, Paris.

Gaspar, J. et al. 1981, 'Futebol, mobilidade geográfica e social', Actas do IX Congresso Internacional

da HISPA (International Association for the History of Physical Education and Sport, Lisboa, pp, 143-159

Joyal, A. 1981, La vie associative et culture populaire, Loisir et société, vol. IV, 1, P.U.Q., Québec, pp. 23-34. 
Joyal, A. 1989, 'Le secteur associatif: une interfaceentre l'économie informelle et formelle', Loisir et société, vol. 12, 1, P.U.Q., Québec, pp. 49-64.

Lanfant, M.-F. 1972, Les théories du loisir, P.U.F., Paris.

Mehel, D. 1982, 'Culture et acteurs associatives', Sociologie du Travail, 1, Paris.

Maget, M. 1971, 'Los rurales', in Dumazedier, J, et al. (org.), Ocio y sociedad de clase, Fontanella, Barcelona.

Parker, S. 1976, The Sociology of Leisure, Londres

Pedro-Rego, P. 1993, O Associativismo e a Identidade Cultural - Uma Perspectiva Localista, Economia e Sociologia, 55, Évora, pp. 177-194.

Sue, R. 1980, Le loisir, Col Que sais-je?, P.U.F., Paris.

Sue, R. 1984, Vers une société du temps libre?, P.U.F., Paris.

Viegas, J. M. L. 1984, Associativismo e Dinâmica Cultural, Sociologia, 1, ICSTE, Lisboa, pp. 103-121. 
Série

Ensino

Imprensa da Universidade de Coimbra

Coimbra University Press

2008

- $\mathrm{U}$

(m) 